\title{
Frigoconservação das pontas de estolões na produção de muda com torrão e frutas de morangueiro
}

\author{
Cold storage of strawberry runner tips on plug plants production and yield
}

\author{
Odair José Schmitt ${ }^{\mathrm{I}}$ Jerônimo Luiz Andriolo" ${ }^{\mathrm{II}}$ Vinícius Toso $^{\mathrm{I}}$ Djeimi Isabel Janisch ${ }^{\mathrm{I}}$ \\ Miriane Dal Picio ${ }^{\mathrm{I}}$ Maíne Alessandra Lerner ${ }^{\mathrm{III}}$
}

\section{RESUMO}

\begin{abstract}
O objetivo do trabalho foi determinar o efeito da frigoconservação das pontas de estolões na produção de plug plants e frutas de morangueiro. $O$ experimento foi realizado em Santa Maria, RS, com mudas das cultivares 'Camarosa', 'Diamante' e 'Arazá', produzidas a partir de pontas de estolões submetidas ao armazenamento refrigerado por $0 ; 7 ; 14 ; 21$; 28; e 35 dias na temperatura de $0,5 \pm 0,3^{\circ} \mathrm{C}$ e umidade relativa de $95 \pm 1 \%$. Após a frigoconservação, as pontas de estolões foram enraizadas para produção de mudas, as quais foram plantadas no solo para produção de frutas. A taxa de sobrevivência e o número de folhas das mudas foram avaliados após o período de enraizamento. $O$ número de frutas e de estolões emitidos e a produção de frutas foram avaliados durante os meses de junho a novembro de 2010. Concluiu-se que a frigoconservação das pontas de estolões para posterior enraizamento e produção de plug plants não afeta o crescimento e a taxa de sobrevivência das mudas. A produção de frutas das plantas oriundas dessas mudas diminui com o aumento do período de frigoconservação, enquanto a emissão de estolões aumenta linearmente, com diferenças entre as cultivares.
\end{abstract}

Palavras-chave: Fragaria x ananassa, propagação, pontas de estolões, plug plants.

\section{ABSTRACT}

The objective of this research was to determine the effects of cold storage of strawberry runner tips used for production of plug plants and fruit yield in the field. The experiment was conducted in Santa Maria, RS, using plug plants rooted after $0 ; 7 ; 14 ; 21 ; 28$ and 35 days of cold storage of runner tips at $0,5 \pm 0,3^{\circ} \mathrm{C}$ temperature and $95 \pm 1 \%$ air humidity. After the cold storage period, runner tips were rooted for plug plant production and planted in the field for fruit production. The survival rate and number of leaves of plug plants were recorded after rooting. Fruit and stolon number and fruit yield were determined from June to December 2010. It was concluded that the cold storage of runner tips for further rooting and plug plant production did not affect growth and survival of plug plants. Fruit yield of plants originated from such plug plants is reduced when the cold storage period is increased while emission of stolons is linearly enhanced, but these effects are cultivar dependent.

Key words: Fragaria $x$ ananassa, propagation, runner tips, plug plants.

\section{INTRODUÇÃO}

Atualmente, na produção de mudas comerciais de morangueiro, utilizam-se dois tipos de mudas. O primeiro, denominado de raízes nuas, consiste em plantar as mudas matrizes no solo desinfestado para que os estolões emitidos enraízem durante a primavera e o verão. Em seguida, as mudas são arrancadas do solo e comercializadas com as raízes nuas. O segundo, denominado de plug plants, consiste em plantar as mudas matrizes fora do solo. As pontas dos estolões emitidas no verão são retiradas e colocadas para enraizar em bandejas com substrato, originando uma muda que é comercializada com torrão (DURNER et al., 2002; SANTOS \& MEDEIROS, 2003b).

'Programa de Pós-graduação em Agronomia, Centro de Ciências Rurais (CCR), Universidade Federal de Santa Maria (UFSM), Santa Maria, RS, Brasil.

IIDepartamento de Fitotecnia, CCR, Av. Roraima, 1000, Campus Universitário, 97105-900, Santa Maria, RS, Brasil. E-mail: andriolo@smail.ufsm.br. Autor para correspondência.

IIICurso de Agronomia, UFSM, Santa Maria, RS, Brasil. 
O método de produção de plug plants vem sendo adotado por viveiristas em diversos países da Europa e América do Norte. Dentre as vantagens, destaca-se o fato de evitar o uso de produtos fumigantes para a desinfestação do solo, obter mudas homogêneas com elevada taxa de sobrevivência após o plantio, atingindo maior precocidade e produtividade de frutas em comparação com as mudas de raízes nuas (DURNER et al., 2002; TAKEDA \& HOKANSON, 2003; HOCHMUTH et al., 2006; GIMENEZ et al., 2008a). Entretanto, exige produção elevada de pontas de estolões em curto espaço de tempo a fim de produzir as mudas comerciais destinadas à renovação anual das lavouras no início do outono. As pontas de estolões emitidas fora do período destinado à produção de mudas são retiradas das plantas matrizes e descartadas, gerando desperdício e necessidade extra de mão-de-obra.

Na produção de plug plants, as pontas de estolões são retiradas da planta matriz antes de enraizarem. Uma alternativa de aproveitamento das pontas de estolões emitidas no início do verão, antes, portanto, do período destinado à produção de mudas comerciais, é o armazenamento em câmara fria para posterior enraizamento. A frigorificação das mudas de morangueiro antes do plantio em temperaturas em torno de $0^{\circ} \mathrm{C}$ a $1,5^{\circ} \mathrm{C}$ por períodos variáveis de tempo é prática comum na Europa e Estados Unidos, com a finalidade de aumentar a produtividade de frutas (KAMPERIDOU \& VASILAKAKIS, 2006). Entretanto, o efeito das baixas temperaturas nas pontas de estolões a serem empregadas na produção de mudas do tipo plug plants tem sido pouco estudado. Os resultados disponíveis indicam redução na taxa de sobrevivência das mudas após frigoconservação por 30 e 60 dias na temperatura de $1^{\circ} \mathrm{C}$ (HOCKANSON et al., 2004) e após 120 dias na temperatura de $-1^{\circ} \mathrm{C} \pm 1^{\circ} \mathrm{C}$ (VERDIAL et al., 2009), devido à necrose dos primórdios radiculares. Na produtividade de frutas, HOCKANSON et al. (2004) não encontraram diferença significativa nesses dois períodos de frigoconservação.

Dentre as principais cultivares de morangueiro utilizadas no Brasil, está a ‘Camarosa' e 'Diamante' (OLIVEIRA et al., 2005). A cultivar 'Camarosa' é originária da Califórnia, EUA, classificada como de dia curto quanto à resposta fotoperiódica (VOTH et al., 1994). A cultivar 'Diamante’é de dia neutro e apresenta boa produtividade, mesmo com pequena exposição a baixas temperaturas (SHAW, 1998). A cultivar 'Arazá' tem sua origem no Uruguai, classificada como de dia curto, com baixa exigência de frio, tolera altas temperaturas no período de indução floral, tendo elevada produção precoce de frutas (GIMENEZ et al., 2002; VICENTE et al., 2004).
Nesse sentido, esta pesquisa teve por objetivo determinar o efeito da frigoconservação das pontas de estolões na produção de plug plants e na posterior produção de frutas de morangueiro.

\section{MATERIAL E MÉTODOS}

O experimento foi realizado em Santa Maria - RS. O período experimental foi de setembro de 2009 a novembro de 2010, com as cultivares 'Camarosa', 'Diamante' e ‘Arazá'.

A aclimatização das mudas matrizes oriundas de propagação in vitro foi realizada no interior de um abrigo de polietileno, no período entre 13 e 26 de outubro de 2009, seguindo a metodologia descrita por BISOGNIN, (2007). Para a produção das pontas de estolões, foi empregado um sistema fechado de cultivo fora do solo em bancadas formadas por telhas de fibrocimento $1,10 \mathrm{~m} \times 3,65 \mathrm{~m}$. As mudas aclimatizadas foram plantadas no dia 26 de outubro, em sacos de polietileno preenchidos com $1,7 \mathrm{dm}^{3}$ do substrato orgânico MECPLANT HF ${ }^{\circledR}$. O fornecimento de água e nutrientes foi realizado por fertirrigação com fita gotejadora, com volume e frequência ajustadas à demanda da cultura (GIMENEZ, 2007).

A partir de 11 de fevereiro de 2010, foram feitas seis coletas de pontas de primeira ordem que apresentavam primórdios radiculares visíveis, nas quais foi determinado o diâmetro de coroa, número de primórdios radiculares e número de folhas expandidas. As datas de coleta foram 11 (T1), 18 (T2) e 25 (T3) de fevereiro, 04 (T4), 11 (T5) e 18 de março de 2010 (T6). As pontas referentes às primeiras cinco coletas foram acondicionadas imediatamente, após a coleta, em sacos plásticos pretos com espessura de 30 micras aproximadamente, com volume de $5 \mathrm{dm}^{3}$ e armazenadas em câmara fria sob temperatura de $+0,5( \pm 0,3)^{\circ} \mathrm{C}$ e umidade relativa de $95( \pm 1) \%$. As pontas de estolões da última coleta não foram submetidas à frigoconservação e foram consideradas testemunhas. As pontas de estolões permaneceram no interior da câmara fria até o dia 18 de março, totalizando 7 (T5); 14 (T4); 21 (T3); 28 (T2) e 35 (T1) dias de armazenamento refrigerado. Nesta data, as pontas foram retiradas da câmara fria e colocadas para enraizar em bandejas de poliestireno de 128 células contendo substrato orgânico MECPLANT $\mathrm{HF}^{\circledR}$. O período de enraizamento foi de 22 dias, sendo as bandejas mantidas no interior do abrigo de polietileno, sob tela de sombreamento com redução de $50 \%$ na transmissividade e irrigação por microaspersão oito vezes ao dia (COCCO et al., 2010).

O plantio no campo para produção de frutas foi realizado no dia 10 de abril de 2010. Ao retirar as mudas das bandejas, foi feita a contagem daquelas 
enraizadas, determinada a taxa de sobrevivência e o número de folhas. A taxa de sobrevivência foi calculada pela diferença entre o número de pontas colocadas nas bandejas para enraizar e o número de mudas formadas. O plantio foi feito no solo, em canteiros cobertos com filme de polietileno opaco preto de 30ìm (mulching), sob túneis baixos de polietileno transparente. A densidade de plantio foi de 12 plantas $\mathrm{m}^{-2}$. O manejo das plantas durante o período de produção de frutas foi feito de acordo com as indicações técnicas para a cultura (SANTOS \& MEDEIROS, 2003a).

O delineamento experimental utilizado foi blocos casualizados com quatro repetições de 20 plantas por parcela. O período de frutificação ocorreu entre 22 de julho e 30 de novembro de 2010. Durante esse período, as frutas, na fase de maturação 87 (MEIER et al., 1994), foram colhidas duas vezes por semana, contadas e pesadas. Os estolões emitidos pelas plantas durante o período foram contados e eliminados. Os resultados foram submetidos à análise da variância, com teste de Tukey ou regressão polinomial, quando pertinente, empregando o software Sisvar (UFLA, versão 4.2).

\section{RESULTADOS E DISCUSSÃO}

Não foram observadas diferenças significativas entre os tratamentos para todas as variáveis avaliadas nas pontas de estolões, coletadas das plantas matrizes para serem submetidas ao armazenamento refrigerado. O número médio de primórdios radiculares foi de 5,3; 4,9; 5,5 e as médias do diâmetro da coroa foram de 4,8; 5,8 e 5,5mm para as cultivares 'Camarosa', 'Diamante' e 'Arazá', respectivamente. O número de folhas por ponta de estolão foi de 1,$6 ; 1,7$ e 1,9, respectivamente. No momento do plantio a campo, ao final do período de enraizamento, não foram observadas diferenças significativas no número de folhas por muda das cultivares 'Camarosa', 'Diamante' e 'Arazá', cujas médias foram de 3,8; 3,6 e 3,9, respectivamente.

Foram observadas diferenças significativas na produção de frutas e na emissão de estolões em resposta aos tratamentos. As cultivares 'Diamante' e 'Arazá' reduziram linearmente em 47,77\% e 19,46\%, respectivamente, a produção de frutas com o aumento do período de armazenamento refrigerado (Figura 1A). A produção mais elevada dessas duas cultivares foi obtida nas plantas cujas mudas originaram-se de pontas que não foram armazenadas. Entretanto, a cultivar 'Camarosa' atingiu a máxima produção estimada de frutas com mudas originadas de pontas de estolões com 12 dias de armazenamento refrigerado. Foi também essa cultivar aquela que atingiu a maior produção de frutas, de 715,49g planta-1, similar àquela obtida no mesmo local com as cultivares 'Oso Grande' e 'Camarosa' em experimentos anteriores (GIMENEZ, 2008b). A partir de 12 dias de armazenamento refrigerado, a diminuição em 39,9\% da produção de 'Camarosa' esteve acompanhada de uma redução do número e peso médio de frutas (Figura 1B-C). Na cultivar 'Diamante', houve somente redução do número de frutas e o peso médio não apresentou diferenças significativas entre os períodos de armazenamento refrigerado, com média de $13,7 \mathrm{~g}$ fruto $^{-1}$ (Figura $1 \mathrm{~B}$ ).

Na produção de mudas de raízes nuas, tem sido considerado que a produção de frutas está relacionada com o número de horas de frio que as mudas recebem nos viveiros, denominado de vernalização (RONQUE, 1998; STAPLETON et al., 2001). Os resultados atuais sugerem que esta relação não existiria quando a produção de mudas é feita através de pontas de estolões. Uma das hipóteses para explicar a diferença no efeito da frigoconservação nas pontas de estolões sobre a produção de frutas refere-se ao balanço hormonal desses dois materiais vegetais. As mudas de raízes nuas são produzidas mediante enraizamento das pontas de estolões, à medida que vão sendo emitidas pela planta matriz e são colhidas no início do outono para plantio das lavouras destinadas à produção de frutas. Nessa fase, tanto a planta matriz como as mudas enraizadas estão no início da fase de repouso vegetativo, que ocorre naturalmente no outono, induzido principalmente pelo fotoperíodo e temperaturas decrescentes (GIMENEZ, 2008a). No balanço hormonal, essa fase caracteriza-se por baixa concentração dos hormônios de crescimento, principalmente auxinas e giberelinas, e concentrações mais elevadas dos hormônios da senescência, como o ácido abscísico (CTIFL, 1997). O acúmulo de horas de frio é o mecanismo natural para reverter essas concentrações e reiniciar o crescimento vegetativo e frutificação. No caso das pontas de estolões, estas são coletadas ainda no verão, quando as plantas matrizes estão em crescimento e, portanto, com elevados níveis de hormônios de crescimento. Isso explica a menor necessidade de frio das mudas produzidas a partir de pontas de estolões, em relação àquelas de raízes nuas. Entretanto, a partir de determinado número de horas de frio, esse efeito pode ser anulado pela respiração das plantas, a qual consome as reservas de assimilados e pode aumentar a mortalidade das mudas antes e no momento do plantio. No trabalho atual, não foram constatadas diferenças na taxa de sobrevivência durante ao período de formação das mudas oriundas dos diferentes tratamentos nas cultivares 'Camarosa', 'Diamante' e 'Arazá', a qual foi de 72,7\%, 74,2\% e 72,9\%, 


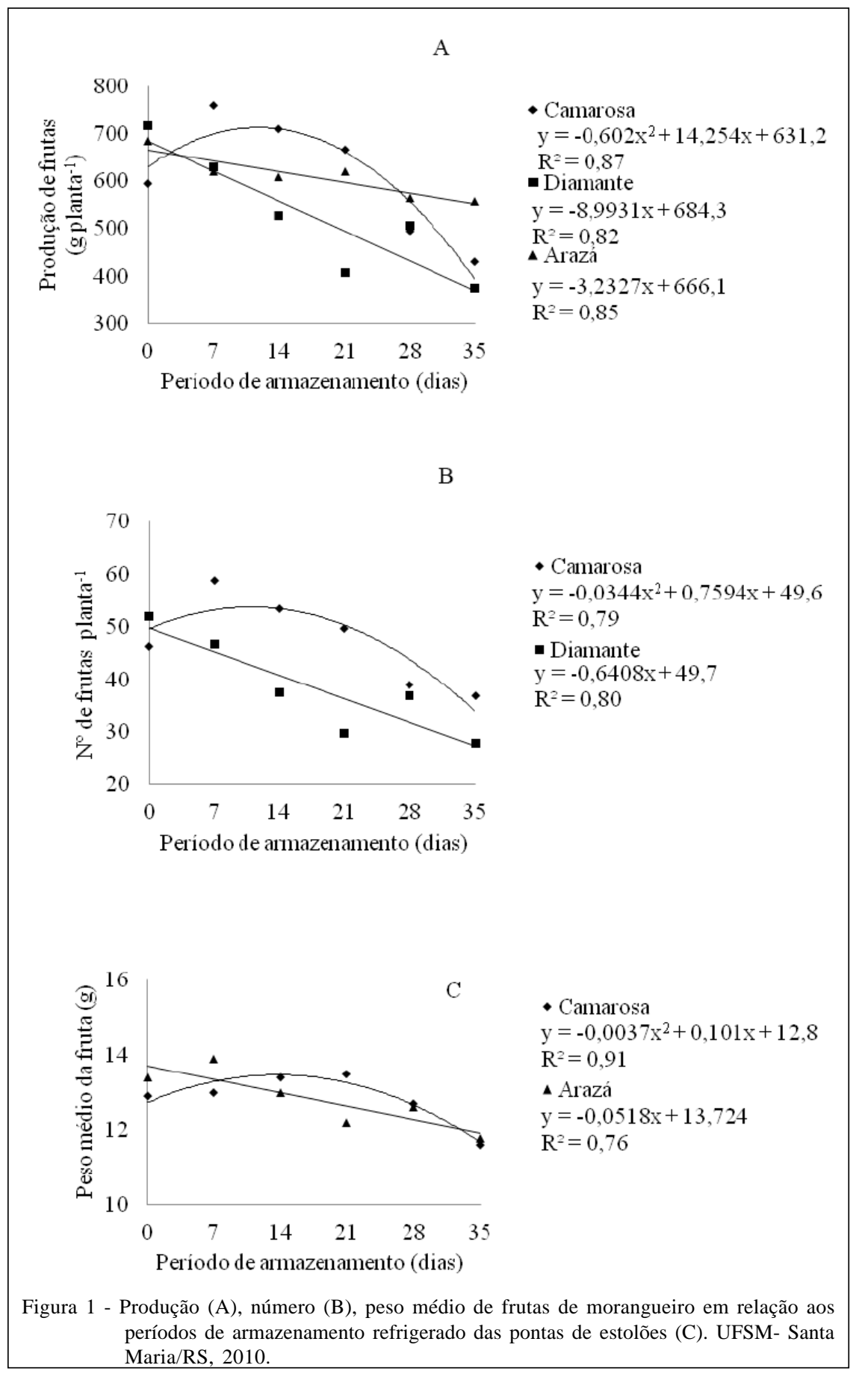

respectivamente. Também não foi constatada mortalidade de plantas na lavoura após o plantio das mudas. Entretanto, HOCKANSON et al. (2004) verificaram que pontas de estolões das cultivares 'Latestar' e 'Allstar' armazenadas a $1{ }^{\circ} \mathrm{C}$ por 1 e 2 meses para posterior produção de mudas apresentaram taxas de sobrevivência de $77 \%$ e $71 \%$, respectivamente. Em São Paulo, VERDIAL et al. (2009) relatam taxas de sobrevivência inferiores a 54\% em mudas das cultivares 'Campinas', 'Dover', 'Sweet Charlie', 'Sequoia’ e 'Pelican' após frigoconservação das pontas de estolões por 120 dias na temperatura de $1^{\circ} \mathrm{C} \pm 1$, concluindo pela inviabilidade dessa técnica naquelas condições. As diferenças na taxa de sobrevivência entre os resultados atuais e aqueles da literatura podem ser atribuídas às condições ambientais após o plantio das mudas na lavoura.

Ciência Rural, v.42, n.6, jun, 2012. 
Durante o período de produção de frutas no campo, foi observado que a emissão de estolões ocorreu desde os 40 até os 93 dias após o plantio. $\mathrm{O}$ armazenamento refrigerado das pontas aumentou linearmente a emissão de estolões nas plantas em fase de produção de frutas. Essa resposta foi mais acentuada nas cultivares de dias curtos 'Camarosa' e 'Arazá' (P>0,05) (Figura 2A). Efeito semelhante foi observado por HOCKANSON et al. (2004) nas cultivares 'Latestar' e 'Northeaster'. A emissão de

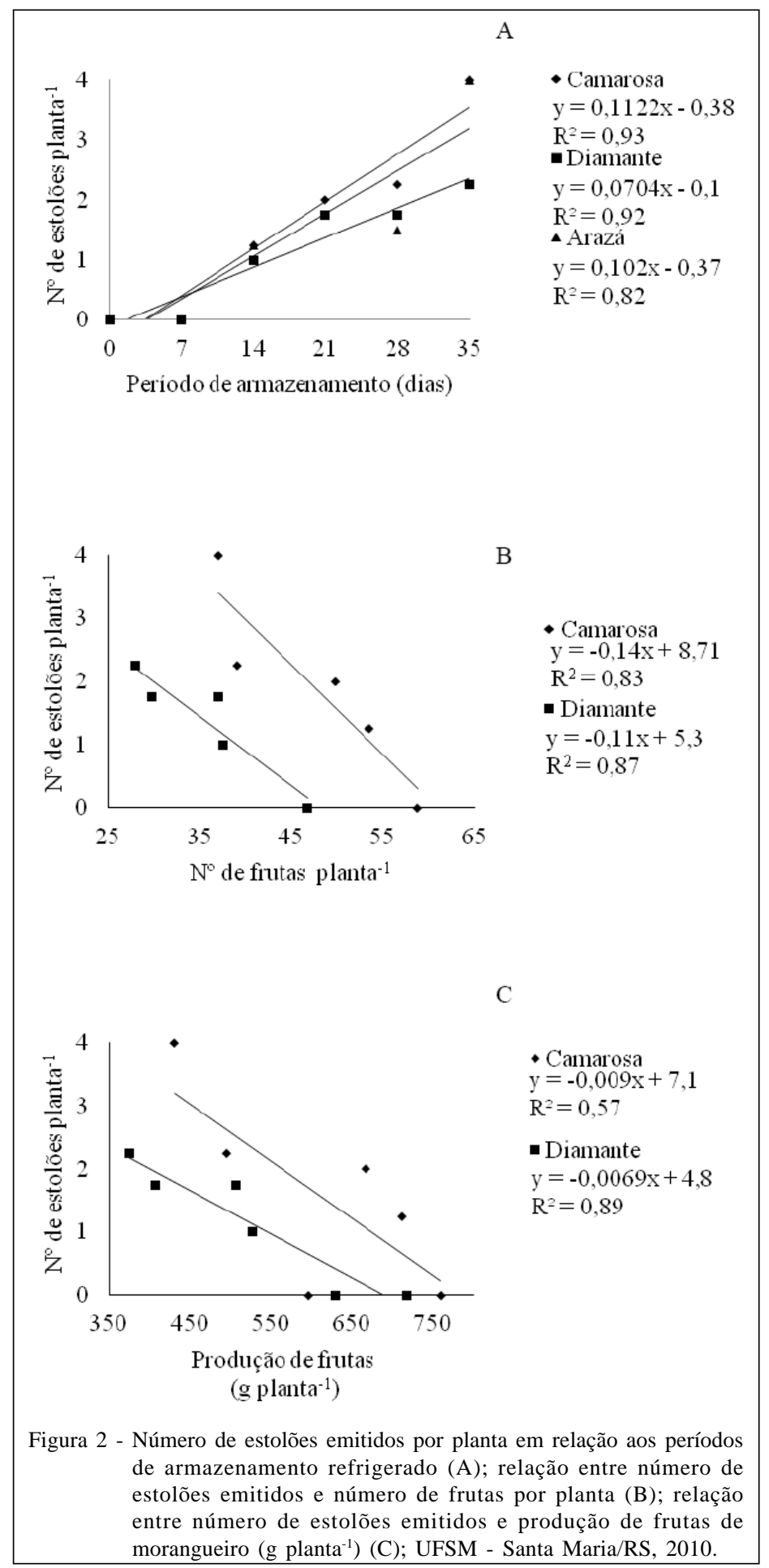

Ciência Rural, v.42, n.6, jun, 2012. 
estolões apresentou relação linear inversa com o número e produção de frutas nas cultivares 'Camarosa' e 'Diamante' (Figuras 2B-C), indicando uma relação de antagonismo entre esses dois processos, conforme relatado na literatura (DURNER \& POLING, 1987; DARNELL \& HANCOCK, 1996; BATTEY et al., 1998). No entanto, essa relação não foi verificada na cultivar 'Arazá'. Esse resultado mostra que o fator cultivar também deve ser levado em conta ao considerar o efeito do armazenamento refrigerado sobre o estolonamento das plantas em fase de produção de frutas.

Do ponto de vista da geração de tecnologia para a produção de mudas de morangueiro pelo método de plug plants, os resultados atuais demonstram que é possível armazenar pontas de estolões sob refrigeração por aproximadamente sete dias sem afetar a produção das plantas. O efeito de períodos mais longos de armazenamento sobre a produção de frutas depende da cultivar. Esse período permite racionalizar a coleta das pontas e o enraizamento nas bandejas para melhor escalonamento da entrega das mudas comerciais aos produtores de frutas. Os resultados atuais geram também dúvidas sobre a necessidade e a conveniência do armazenamento no frio das pontas de estolões. Embora, na cultivar 'Camarosa', o armazenamento a frio por 12 dias tenha aumentado a produção de frutas em $16,8 \%$, esse acréscimo de produção pode não ser suficiente para cobrir os custos do armazenamento refrigerado. A diminuição na produção de frutas acompanhada do aumento da emissão de estolões em consequência do aumento das horas de frio no armazenamento indica que não haveria vantagens em fazer a produção de mudas pelo método de plug plants em regiões de altitude, conforme tem sido recomendado no zoneamento agroclimático para produção de mudas de morangueiro de raízes nuas no estado do Rio Grande do Sul (WREGE et al., 2007). Essa possibilidade traria vantagens ao segmento produtivo, porque permitira localizar a produção de mudas em regiões próximas àquelas da produção da fruta. Outra possibilidade seria que cada produtor de frutas produzisse suas próprias mudas, a partir de plantas matrizes adquiridas especialmente para essa finalidade.

\section{CONCLUSÃO}

A frigoconservação das pontas de estolões para posterior enraizamento e produção de plug plants não afeta o crescimento e a taxa de sobrevivência das mudas. A produção de frutas das plantas oriundas dessas mudas diminui com o aumento do período de frigoconservação enquanto a emissão de estolões aumenta linearmente, com diferenças entre as cultivares.

\section{AGRADECIMENTO}

Ao Conselho Nacional de Desenvolvimento Científico e Tecnológico (CNPq), pelo apoio financeiro sob número de concessão 470255/2009-9 e uma bolsa PIBIC para Odair José Schmitt.

\section{REFERÊNCIAS}

BATTEY, N.H. et al. Genetic and environmental control of flowering in strawberry. In: COCKSHULL, K.E. et al. (Eds.). Genetic and environmental manipulation of horticultural crops. Cambridge, U.K: CAB International, 1998. p.111-131.

BISOGNIN, D.A. Produção de plantas matrizes de morangueiro. In: ANDRIOLO, J.L. (Ed.). SEMINÁRIO SOBRE O CULTIVO HIDRÔPONICO DE MORANGUEIRO, 2007, Santa Maria, RS. Anais... Santa Maria: UFSM, 2007. p.9-17.

CTFIL. Centre Technique Interprofessionele des Fruits e Legumes. La fraise: plant et varietés. Paris, 1997. 103p.

COCCO, C. et al. Development and fruit yield of strawberry plants as affected by crown diameter and plantlet growing period. Pesquisa Agropecuária Brasileira. v.45, n.7, p.730-736, 2010. Disponível em: <http://www.scielo.br/ scielo.php? script=sci_art text \& pid=S 0100 204X2010000700014\&lng=pt\&nrm=iso\&tlng=en>. Acesso em: 29 ago. 2011. doi: 10.1590/S0100-204X2010000700014.

DARNELL, R.L.; HANCOCK. J.F. Balancing vegetative and reproductive growth in strawberry. In: PRITTS, M.V. et al. (Eds.). NORTH AMERICAN STRAWBERRY CONFERENCE, 4., Gainesville, FL; 1996. Proceedings... Gainesville, FL: Hort. Science, 1996. p144-150.

DURNER, E.F.; POLING. E.B. Flower bud induction, initiation, differentiation, and development in the 'Earliglow' strawberry. Scientia Horticulturae, v.31, p.61-69, 1987. Disponível em: <http://www.sciencedirect.com/science/article/pii/ 0304423887901075>. Acesso em: 22 jan. 2011. doi:10.1016/ 0304-4238(87)90107-5.

DURNER, E.F. et al. Recent advances in strawberry plug transplant technology. HortTechnology, v.12, n.4, p.545550, 2002. Disponível em: <http:// horttech.ashspublications.org/cgi/reprint/12/4/ 545 ? maxtoshow $=$ \&hits $=10 \&$ RESULTFORMAT $=\&$ author $1=$ durner\&searchid=1\&FIRSTINDEX=0\&sortspec=relevance \& resourcetype=HWCIT $>$. Acesso em: 05 jun. 2011.

GIMÉNEZ, G. Produção de mudas de morangueiro em hidroponia. In: SEMINÁRIO SOBRE O CULTIVO HIDROPÔNICO DE MORANGUEIRO, 2007, Santa Maria, RS. Anais... Santa Maria: UFSM, 2007. p.18-29.

GIMÉNEZ, G. et al. Closed soilless growing system for producing strawberry bare root transplants and runner tips. Pesquisa Agropecuária Brasileira, v.43, n.12, p.1757-1761, 2008a. Disponível em: <http://www.scielo.br/ scielo.php? script = sci_art t ext \& pid = S 0100 204X2008001200016>. Acesso em: 8 jan. 2011. doi: 10.1590/ S0100-204X2008001200016. 
GIMENEZ, G. Seleção e multiplicação de clones de morangueiro (Fragaria $x$ ananassa Duch.). 2008b. 119f. Tese (Doutorado em Agronomia)- Curso de Pós-graduação em Agronomia, Universidade Federal Santa Maria, RS.

GIMENEZ, G. et al. El cultivar de frutilla INIA 'Arazá'. Uruguay: Instituto Nacional de Investigación Agropecuaria. 2002. 4p. (Hoja de divulgación, n. 83).

HOCHMUTH, G. et al. Containerized strawberry transplants reduce establishment-period water use and enhance early growth and flowering compared with bare-root plants. HortTechnology, v.16, n.1, p.46-54, 2006. Disponível em: $<$ http://horttech.ashspublications.org/cgi/reprint/16/1/ 46 maxtoshow $=$ \&hits $=10$ \& RESULTFORMAT $=$ \&author $1=\mathrm{H}$ OCHMUTH\&andorexactfulltext=and\&searchid=1\&FIRSTINDEX=0 \&sortspec $=$ relevance $\&$ resourcetype $=$ HWCIT $>$. Acesso em: 17de jan. 2011.

HOKANSON, S.C. et al. Influence of plant storage duration on strawberry runner tip viability and field performance. HortScience, v.39, n7, p.1596-1600, 2004. Disponível em: <http://hortsci.ashspublications.org/cgi/reprint/39/7/ 1596?maxtoshow=\&hits=10\&RESULTFORMAT=\&author1=HOKANSON $\% 2 \mathrm{C}+$ S.C. + \&andorexactfulltext $=$ and $\&$ searchid $=1 \&$ FIRSTINDEX $=$ $0 \&$ sortspec $=$ relevance $\&$ resourcetype $=$ HWCIT $>$. Acesso em: 17 jan. 2011

KAMPERIDOU, I.; VASILAKAKIS, M. Effect of propagation on some quality attributes of strawberry fruit (Fragaria $x$ ananassa, var. Selva). Scientia Horticulturae, v.107, p.137142, 2006. Disponível em: <http://www.sciencedirect.com/ science/article/pii/S0304423805002372>. Acesso em: 22 jan. 2011. doi: 10.1016/j.scienta.2005.06.009.

MEIER, U. et al. Phänologische Entwick-lungsstadien des Kernobstes (Malus domestica Borkh. und Pyrus communis L.), des Steinobstes (Prunus-Arten), der Johannisbeere (RibesArten) und der Erdbeere (Fragaria $x$ ananassa Duch.). Nachrichtenblatt Deutscher Pflanzenschutzdienst, v.46, p.141-153, 1994

OLIVEIRA, R.P. et al. Mudas certificadas de morangueiro: maior produção e melhor qualidade da fruta. A Lavoura. Rio de Janeiro, v.108, n. 655, p.35-38, 2005.

RONQUE E.R.V. Cultura do morangueiro; revisão e prática. Curitiba: Emater, 1998. 206p.
SANTOS, A.M.; MEDEIROS, A.R.M. (Eds). Morango. Produção. Frutas do Brasil, 40. Brasília-DF: EMBRAPA CT, 2003a. 81p.

SANTOS A.M.; MEDEIROS A.R.M. Produção de mudas comerciais. In: _ ; _ _ (Eds.). Morango; produção. Brasília: Embrapa Informação Tecnológica. 2003b. p.35-38. (Embrapa Informação Tecnológica. Frutas do Brasil, 40).

SHAW, D.V. Strawberry plant 'Diamante'. United States Plant patent. PP10435. 9 June 1998. Disponível em: www.freepatentsonline.com/PP10435.html. Acesso em: 22 jan. 2011.

STAPLETON S.C. et al. Transplant source affects fruiting performance and pests of 'Sweet Charlie' strawberry in Florida. HortTechnology, v.11, p.61-65, 2001. Disponível em: <http:/ /horttech.ashspublications.org/cgi/reprint/11/1/61>. Acesso em: 23 maio, 2011.

TAKEDA, F.; HOKANSON S.C. Strawberry fruit and plug plant production in the greenhouse. Acta Horticulturae, (ISHS) n.626, p.283-285, 2003. Disponível em: <http:// ddr.nal.usda.gov/dspace/bitstream/10113/40094/1/ IND43793621.pdf $>$. Acesso em: 22 jan. 2011. doi: IND43793621.

VERDIAL, M.F. et al. Fisiologia de mudas de morangueiro produzidas em sistema convencional e em vasos suspensos. Revista Brasileira Fruticultura, v.31, n.2, p.524-531, 2009. Disponível em: <http://www.scielo.br/ scielo.php ? script = sci_art text \& pid = S 0100 29452009000200029>. Acesso em: 30 maio, 2011. doi: $10.1590 / \mathrm{S} 0100-29452009000200029$

VICENTE, E. et al. Avances del programa de mejoramiento genético de frutilla en Uruguay. In: SIMPÓSIO NACIONAL DO MORANGO, 2.; ENCONTRO DE PEQUENAS FRUTAS E FRUTAS NATIVAS DO MERCOSUL, 2004, Pelotas, RS. Palestras... Pelotas, RS: EMBRAPA, 2004. p.37-44. Disponível em: <http://www.cpact.embrapa.br/publicacoes/ download/documentos/documento_124.pdf >. Acesso em: 30 maio, 2011.

VOTH, V. et al. Strawberry plant called 'Camarosa'. United States Plant patent. PP8708 3 May 1994. Disponível em: <www.patentgenius.com/patent/PP8708.html>. Acesso em: 22 jan. 2011.

WREGE, M.S. et al. Zoneamento agroclimático para produção de mudas de morangueiro no Rio Grande do Sul. 2007. Disponível em: <http://www.cpact.embrapa.br/ publicacoes/download/documentos/documento_187.pdf $>$. Acesso em: 20 jun. 2011. 